\title{
An Exploration into Technological Capabilities among Early Stage Indian Product based Telecom Start-ups
}

\author{
Prageet Aeron \\ Rekha Jain
}

W.P. No. 2011-02-06

February 2011

The main objective of the working paper series of the IIMA is to help faculty members, research staff and doctoral students to speedily share their research findings with professional colleagues and test their research findings at the pre-publication stage. IIMA is committed to maintain academic freedom. The opinion(s), view(s) and conclusion(s) expressed in the working paper are those of the authors and not that of IIMA.

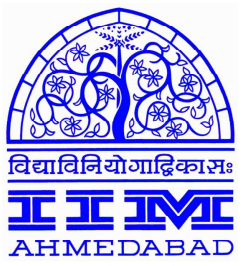

INDIAN INSTITUTE OF MANAGEMENT

AHMEDABAD-380 015

INDIA 


\title{
An Exploration into Technological Capabilities among Early Stage Indian Product based Telecom Start-ups
}

\author{
Prageet Aeron \\ Assistant Professor, Jindal Global Business School, Sonepat, Haryana, India \\ Email: paeron@jgu.edu.in \\ (All correspondence to be sent at this e-mail id) \\ Dr. Rekha Jain \\ Professor and Idea Telecom Executive Chair \\ Indian Institute of Management, Ahmedabad, Gujarat, India \\ Email: rekha@iimahd.ernet.in
}

\begin{abstract}
New technology based start-ups play a very important role in developing the economy of a country. In India, telecom sector has seen unprecedented growth over the last decade and this has led to emergence of several telecom related start-ups. However, product based B2B start-ups are rare and existing ones have to undergo several challenges in commercializing. Surprisingly not much research work has been undertaken in identifying capabilities among early stage start-ups although the early phase represents a very crucial phase for product based firms and has been known to determine the success or failure for start-ups. Present study explores the technological capabilities that enable commercialization among such early stage start-ups by adopting a multiple case (four independent cases) based inductive methodology with Indian telecom start-ups as the context. We have identified architectural design, algorithmic implementation and product adaptation as components of technological capability of such start-ups. We further drill in to each of the sub-components of the technological capabilities to unearth their antecedents and peculiarities in telecom product company context. As a result we also present a classification scheme for studying the product architecture in the telecom context. We analyze and point out differences in technological capability among telecom start-ups vis-à-vis established firms in the sector.
\end{abstract}

Keywords: Entrepreneurship; Telecom based new ventures; Identifying technological capabilities. 


\section{An Exploration into Technological Capabilities among Early Stage Indian Product based Telecom Start-ups}

\section{Introduction:}

Technology based new ventures have been known to play a significant role in the development of economy of any country especially in today's knowledge based environment. It has been shown by extensive research that such new firms grow more and distribute wealth more effectively as compared to established firms (Schumpeter, 1934, 1942; Wagner, 1994; Tether and Massini, 1998; Brixy and Kohaut, 1999). However, technology based ventures face greater roadblocks in their quest towards commercialization due to volatile and uncertain environment. Extant literature has shown that commercialization marks a very important milestone for any start-up in its lifecycle with a substantial number failing to make the mark (Reynolds and Miller, 1992; Carter, Gartner and Reynolds, 1996). But existing literature has little to offer about how the start-ups reach commercialization and what skills and resources aid in the process both from theoretical as well as practical point of view.

Present work looks into identification of commercialization enabling technological capabilities among early stage technology based start-ups. Our primary contribution to theory is to bring together two threads of literature i.e., resource-based view and entrepreneurship to lay a foundation for studying capabilities in a start-up context. We establish framework for identifying technological capabilities among the start-ups and also specify differences between technological capabilities of established firms and start-ups. We also present details of sub-components of the identified technological capabilities. Our work thus contributes to theory development related to technological capability identification among start-ups in a high-tech context and also helps entrepreneurs in identifying problems and bottlenecks faced by such firms.

In the Indian scenario, telecom as a sector has shown consistent double digit growth since 2002 (IIR, 2009). This growth coupled with rapid technological changes and changing customer preferences have led to several business opportunities. As a result several telecom related start-ups have sprung up across the country. However, majority of such start-ups have a services outlook as they have spun off from the Information Technology sector of India, which has established itself as the back office for services being offered across the globe. Although telecom equipment market for 2008-09 in India has touched USD 30 billion $^{1}$ but still firms have been reluctant to enter high end product development market.

\footnotetext{
${ }^{1}$ Source TEMA website, http://tematelecom.net/upload_images/315TEMA.pdf accessed on 16/09/2009
} 
The product based start-ups have telecom/Internet service providers (TSP/ISPs) or other enterprises as customers and therefore are business to business (B2B) firms. Indian telecom start-ups face several problems in their quest to commercialize namely, acquisition of knowledge, manufacturing and development, testing etc. with their limited funding and un-supportive ecosystem especially for hardware related work. Moreover, competition for such players comes from deep pocketed MNCs such as Nokia-Siemens or Huawei which makes such firms more vulnerable to being wiped out. But these start-ups need to be nurtured as they are bound to play an important role in the Indian economy. According to Indian telecom equipment manufacturers' association (TEMA) the telecom equipment and software industry could generate 10 million jobs directly or indirectly and contribute to $10 \%$ of total gross domestic product (GDP) in the coming 5-10 years.

The rest of the paper is organized as follows. We begin with a brief literature review to emphasize on our theoretical research context, then we discuss our methodology wherein we also discuss our analysis framework, subsequently we present brief case descriptions. We then present detailed analysis based on our case studies to identify technological capabilities and further drill into identified capabilities to understand their sub-components and differences with respect to established firms. We finally end with conclusions where we also report other pertinent observations about the telecom startups.

\section{Literature review:}

The literature on capability identification and evolution has the resource-based view (RBV) at its core. RBV identifies heterogeneity among the firms due to valuable, rare, inimitable, and non-substitutable resources as the source of sustainable competitive advantage (Amit and Shoemaker, 1993; Barney, 1991; Wernerfelt, 1984; Peteraf, 1993) and views firms as bundles of resources. RBV has been extensively used to explain the differences in performance of firms in same sectors which is attributed to idiosyncratic or tacit internal capabilities. Over the years conceptual and empirical work has established that the development of capabilities is difficult, time consuming, expensive and risky because the outcomes may be highly uncertain (Dierickx and Cool, 1989; Helfat, 2000; Karim and Mitchell, 2000). For capabilities to be relevant to managers and researchers, measures of these capabilities need to be developed at the firm level, and as such, identifying and measuring organizational capabilities has become an integral part of research efforts (Henderson and Cockburn, 1994; Deeds et al, 2000).

Over the years scholars have looked at technological capabilities in different ways. Conceptually, Bell and Pavitt (1993) define technological capabilities as the resources needed to generate and manage 
technological change, including skills, knowledge and experience, and institutional structures and linkages. Dosi and Teece (1993) added a more operational perspective when they defined technological capability as the ability to develop and design products and processes, and to operate facilities effectively. Patel and Pavitt (1997) explored the technological capabilities present among 400 of the world's largest firms and conclude that technological capabilities among such firms are multi-field, highly differentiated and stable, and rate of search is influenced by principal product and home country. Danneels $(2002,2007)$ looks at technological competence ${ }^{2}$ among high tech firms from the perspective of innovation literature and emphasizes on leveraging of technological and customer competence to develop new product which also enables renewing existing competence of the firms. Above scholarly works also establish complexity, path dependence and the technological diversity of the established companies as the companies seem to own patents or possess skills not just in their principal product area but also other allied and even non-allied areas. However, these works do not dwell deeper to identify technological capabilities within a particular industry or firm level capabilities.

Among work focusing on an industry level, Prencipe (2000) has operationalized technological capability as breadth and depth of technology, with breadth referring to the diverse technological fields in which the firm is active and the depth dimension dealing with two different levels of component design (context being engine control systems in aircraft industry). Figueiredo (2002) has studied technological capability among two Brazilian steel manufacturers and identified differing technological capability accumulation paths adopted by the firms and further utilized the framework to point out inter-firm capability differences. Afuah (2002) has studied firm's technological capability in the context of pharmaceutical industry and tried to map these capabilities into customer value and competitive advantage. Afuah in his work has also included combination/re-combination of components, linkages between the components, methods, processes and techniques, and underpinning core concepts to offer products with desirable characteristics as a part of technological capability.

An interesting approach operationalizing technological/R\&D capability has been stochastic frontier estimation (SFE) (Dutta et al., 2005) approach wherein capability is conceptualized as efficiency in the transformation of input into outputs relative to a benchmark firm. Dutta et al. (2005) measure R\&D capability of various firms in the semiconductor market and conclude that common factors are unable to explain the heterogeneity of firms being captured by the error term of the model. Several other industry focused empirical works (Henderson and Clark, 1994; Yeoh and Roth, 1999) have operationalized the technological/R\&D capabilities in terms of patents or $R \& D$ expenditure to

\footnotetext{
${ }^{2}$ In present work we consider competence and capability as interchangeable
} 
establish the important link between technological capability of the firm and firm performance. However, none of the above scholarly works has looked at telecom sector/firms in particular. Moreover, although industry focused literature is more informative but it is completely focused on the established firms and not on studying the technological capabilities among the start-ups.

Literature on technological capabilities among start-ups is scarce and like in the case of established firms is focused on citations (Deeds et al., 2000), patents (Tsai, 2004; Lee et al, 1999), R\&D labour and $\mathrm{R} \& \mathrm{D}$ expenditure by individual companies as research focus has been developed countries like the US or the UK. But all these parameters including patents, citations and R\&D spend are inadequate in the context of Indian and other start-up companies in the developing countries as start-ups in such places are not as patent intensive as their counterparts in developed counties. Often such start-ups are hard pressed for finances and they actually see patenting as cumbersome and resource intensive process during the early days. Patel and Pavitt (1997) have pointed out additional limitations of patent and citation based research on technological capabilities such as external technology linkages not getting addressed, tacit component of technology which may actually form the inimitable and valuable component not getting addressed and lastly software related capabilities not getting captured through patents and citations. In a start-up firm expenditure is essentially on the development work and in this scenario R\&D expenditure cannot be separated from development related expenditure.

This would mean firstly that all the expenditure is actually R\&D expenditure and secondly going by the indicator characteristics the higher is the development expenditure higher is the level of technological capability present with in the firm. Both the above conclusions seem out of place.

So there is a need for identifying better indicators of technological capability among the start-ups in the developing country context. A promising paradigm in this respect looking to measure technological capability is the $3 \mathrm{P}$ (product, process and practice) approach (Upadhyayula, Basant, Chandra, 2006) and it been used in understanding the differences in capabilities of electronics based firms within and outside a industrial cluster but the approach has yet not been exploited in early stage firms.

To summarize, still existing literature does not present any framework to clearly identify technological or other capabilities and this represents a grey area in the literature. Most work to date has focused on technological capabilities of established firms ignoring the start-ups and even among the start-ups scholarly work has been overtly focused on patents, citations and R\&D expenditure which are not appropriate to identify tacit technological capabilities among the start-ups. Moreover, there has been no work on telecom sector which involves an intermingling of software and hardware knowledge and is a highly regulated sector not just in India but across the world. In the present work 
we address the above research gaps and focus on identification of technological capabilities among telecom start-ups. For the present work we define technological capabilities as follows;

Technological capabilities for start-ups are a collection of skills, resources, routines or processes that enable them to design and develop the desired product and thereby bestow competitive advantage to the start-ups.

Specifically, we are looking to answer the following research questions through this work,

1. How can technological capabilities be identified among the product based start-ups?

2. What constitutes technological capability among the product based B2B Indian telecom startups that enable commercialization in an Indian context?

3. What are the drivers and sub-components of the identified capabilities?

\section{Method:}

\subsection{Research design:}

We use a multiple case based inductive approach to answer the questions posed by us based on following reasons;

a) Extant literature has been unanimously established that capabilities are strongly connected to the context (Grant, 1996; Teece, Pisano and Shuen., 1997; Eisenhardt and Martin, 2000). In order to unravel capabilities among start-ups it is important to understand the context and case study as a method enables better understanding of the context.

b) Scholars in the field (Teece, Pisano and Shuen., 1997; Eisenhardt and Martin, 2000; Montealegre, 2002; Pan, Pan and Hsieh, 2006) have called for longitudinal case based studies to better understand capability related research questions.

c) Case based study is ideally suited to answer questions related to process inquiry as well as answering in depth explorative how and why kind of questions (Eisenhardt, 1989; Yin, 1994; Eisenhardt and Graebner, 2007).

Choice of cases or sampling is critical stage for multiple case based studies. For the purpose, we identified 12 companies within the telecom sector (through entrepreneur network) operating in different domains such as voice over Internet Protocol (VoIP) platform development, technology platform for offering value added services and equipment manufacturers. To fulfill our objectives we were looking at the firms with following attributes. The companies had to be product companies looking to sell their end product to either telecom/Internet service providers or other enterprises and 
none of them was to be purely a services based company. Since we were interested in understanding technological capabilities leading to commercialization, we needed early stage firms which already had customers and were in the market for at least a year. A time window of 3-4 years from inception of the firm was considered adequate as beyond that the firm moves to a growth stage. The companies had to have their registered corporate head offices in India. The reason for the above filter was that companies started out of India would face a different external environment in terms of the ability to raise capital as well as the risk appetite of the entrepreneurs and investors as compared to those based in US or UK. The companies had to be independent and not promoted by any large diversified conglomerate as a company promoted by such group would be a diversification move rather than a start-up.

We sent letters to all the 12 identified companies obtained from their respective websites and sent mails to them identifying ourselves and explaining the purpose of our work. We requested each of the companies to let us have a session with each of the co-founders to understand and assess the evolution of their firms over the years. Of the 12 firms three chose not to respond and two were found to be services oriented firms. Miles and Huberman (1994); Pettigrew (1988) and Eisenhardt (1989) have advocated maximum variation or polar sample as an aid in developing more robust and generalizable theory. Another important issue in case based research is the number of cases and it has been recommended (Eisenhardt, 1989; Eisenhardt and Graebner, 2007) that four cases upwards is a good number for theory development if dealt in a rigorous and detailed manner. Based on above, of the remaining we chose four firms based on fundamental differences in terms of specific observable parameters (see table 1). Although we began with a sample size of four firms we kept the option open for more just in case our data did not show incremental saturation after the detailed content analysis of our fourth case study. Among the four companies one of the companies (C3) is no longer in existence and had to be closed down due to various business reasons even before we started our work. This company is of special significance in our work as it could help us in identifying any divergent pattern amongst the other firms. 
Table-1: Sample firms with differences across various parameters

\begin{tabular}{|c|c|c|c|c|}
\hline & \multicolumn{4}{|c|}{ Company Name } \\
\hline Parameter & $\overline{\mathrm{C} 1}$ & $\overline{\mathrm{C} 2}$ & $\mathrm{C} 3$ & $\mathrm{C} 4$ \\
\hline Technology & $\begin{array}{l}\text { WiMax } \\
\text { (wireless) }\end{array}$ & VoIP & $\begin{array}{l}\text { Circuit } \\
\text { emulation } \\
\text { over Ethernet }\end{array}$ & $\begin{array}{l}\text { Bluetooth } \\
\text { (wireless) }\end{array}$ \\
\hline Area of operation & $\begin{array}{l}\text { Equipment } \\
\text { development }\end{array}$ & $\begin{array}{l}\text { Platform } \\
\text { development }\end{array}$ & $\begin{array}{l}\text { Equipment } \\
\text { development }\end{array}$ & $\begin{array}{l}\text { Platform } \\
\text { development }\end{array}$ \\
\hline Hardware/software & Both & Software & Both & Both \\
\hline Incubation & No & Yes & Yes & No \\
\hline VC investment & No & Yes & Yes & Yes \\
\hline \begin{tabular}{lll}
\multicolumn{2}{l}{ Customers } \\
(Tech Vs & Non \\
Tech) & & \\
\end{tabular} & $\begin{array}{l}\text { ISP/TSP } \\
\text { (Tech) }\end{array}$ & $\begin{array}{l}\text { ISP/TSP } \\
\text { (Tech) }\end{array}$ & $\begin{array}{l}\text { ISP/TSP } \\
\text { (Tech) }\end{array}$ & $\begin{array}{l}\text { Community center, } \\
\text { retail malls (Non- } \\
\text { Tech) }\end{array}$ \\
\hline Patents & $\begin{array}{l}\text { Yes } \\
\text { (Patent } \\
\text { Pending) }\end{array}$ & No & Yes & $\begin{array}{l}\text { Yes } \\
\text { (Patent Pending) }\end{array}$ \\
\hline Success/Failed & Success & Success & Failed & Success \\
\hline
\end{tabular}

Our data collection was spread over a year wherein we conducted 2-3 rounds of interviews across the four firms. Since we were studying start-ups (max team size 30, min team size 16) the founding members formed primary respondents as they are most well informed about each activity in the firm. In first round we interviewed the founders in all four firms separately and our interview questions (semi-structured) were focused on technological trajectory followed by the firm and associated decision making (interview duration varied from 45 mins to 2 hours). Subsequently in second or third round we also talked to senior managers apart from founding members wherever need was felt for the same (about 3-4 members in each firm were interviewed). We also collected company related documents (product details, meeting details, e-mails etc.) which helped in triangulation of collected data. We also interviewed five external experts (themselves well known entrepreneurs in the sector) both from industry and academia to enhance our understanding about the telecom start-ups and issues faced by such firms. Once data was collected the interviews were transcribed verbatim (250 pages) and converted to case histories. The case histories so prepared were sent to respective firms for their approval in establishing an authentic description of chain of events before further analysis.

\subsection{Analysis framework:}

In our literature review section we have pointed out that no comprehensive framework has been proposed for identifying capability among firms leave alone start-ups. In order to identify the technological capabilities we need to closely examine the technological activities across the firms. Our implicit assumption here is that technological capability will be manifested in the technological activities undertaken by the firm. If certain technological activity, skill or routine that the firm has 
accomplished in its own way has played an important role in commercialization or bestowed a competitive advantage, then such an activity or skill is a candidate for further study and will be considered for detailed analysis exploring the drivers and sub-components of such activity. However, if some activity is considered below par by the entrepreneurs then we do not consider that activity for further study and eliminate it from the set. As a part of theoretically grounding our arguments we invoke fragmented literature on capabilities in this respect which we have collated together and structured in our context. The point we make here has also been indirectly emphasized upon by scholars in the domain that, just a presence of certain activity cannot make it a capability but certain level of excellence or maturity has to be achieved with respect to the process of the activity and its outcomes (Helfat and Peteraf, 2003; Winter, 2003; Helfat et al., 2007; Schreyogg and Kliesch). Summarizing the above discussion, as a first step; three important attributes of the activities that help in identifying technological capability are that the activity should have,

- Made critical contribution to the commercialization process

- Been performed well consistently leading to competitive advantage (Helfat and Peteraf, 2003; Winter, 2003)

- Evolved into identifiable routines overtime (Nelson and Winter, 1982)

As a second step of cross case analysis we dwell deeper into identified activities among the firms to unearth patterns regarding technological capabilities of the telecom start-ups.

This enabled development of conceptual clusters which subsequently were sharpened iteratively by using memos to present emergent themes which then led to the development of certain propositions. From the perspective of presentation we move back and forth between data and theory like it is the standard practice in most works on theory building. We present evidence in the form of quotes and examples from case studies to back up our arguments.

However, it needs to be mentioned here that a limitation of the above process is that it has the danger of suffering from entrepreneur's bias towards certain skills or activities as they might be overemphasized in hindsight. We wave tried to minimize the bias by talking to most members of the founding teams and getting their opinions as well thereby achieving triangulation. In cases where this has not been possible we have taken a call based on our understanding of the case. In the next section we present a short description of the four sample firms. 


\section{Case Studies:}

\subsection{Company C1:}

C1 was founded in Bangalore in the year 2005. The two founding members were highly educated with post graduate degrees in technology; one had a MS from US and other was a MS from India. Both founding members were first generation entrepreneurs without any prior start-up experience. The founders worked for well known telecom related companies which included exposure to both hardware as well as software. The main driver of business was that wireless broadband using WiMax would be the way to go for the future and entrepreneurs expected a huge pent up demand for broadband. So the team decided to get into manufacturing of small base stations (BS). One of the founders took on the role of CEO whereas the other donned the role of CTO.

They developed a small BS using the chipset used by Wavesat (semiconductor manufacturer) for their customer premise equipment and this BS could be mounted on a tower or house top. The company went along with its development work and was able to bring its product into the market and is today among admired start-ups in the field of WiMax from India. In 2008, company had about 30 employees and had already sold its product to a company each in Canada and France. C1 mostly sold through a licensing model wherein they licensed their software and recommended specific hardware to their customers. However, the company could not solicit funds from any venture capitalist and was completely funded by the promoters which has restricted its growth due to lack of funds.

\subsection{Company C2:}

C2 was founded in the year 2000-2001 in Hyderabad. Both the founders were highly educated with post graduate degrees in management; one also had a BS degree in engineering. Both the founding members were first generation entrepreneurs without any prior start-up experience. One founder had prior experience working for a software MNC as a project manager and then for an Indian ISP as the business development in-charge whereas the other founder had sales and marketing experience for the web services division of an ISP. Both the founders gave up their job to start the new company. The first founder became the CTO and the other was designated as the CMO (Chief Marketing Officer).

During this time regulation was passed making VoIP (Voice over Internet Protocol) services legal between PCs in India to phones, mobiles and PCs abroad. The founders found VoIP services to be an ideal opportunity for them to be able to use their technological skills. The business idea was to develop VoIP infrastructure for ISPs who already had network and other infrastructure of their own 
and let them offer the VoIP services using the product developed by the company. The pivotal innovation behind the company was the development of soft-switch with de-coupled application server and front end, which allowed easy transition between protocols. C2 became the first company to offer end to end VoIP infrastructure among the Indian companies. Later the company got invested by a VC based in Coimbatore and shifted its base to Chennai under the aegis of the TeNeT group of IIT Madras. By 2005 the company had acquired several clients both in India and abroad, had become self sustainable and was planning to diversify into platform provider for the various TSPs. Primary revenue model was licensing based. The number of employees was maintained at around 30 even with a regular attrition. $\mathrm{C} 2$ has been one of the pioneers of VoIP products in India and is a unique company of its kind in India.

\subsection{Company C3:}

C3 was founded in late 2002 in Mumbai. All the three founders were highly educated one with a PhD (electrical engineering), second with an MBA from US and the third holding a post graduate degree (electrical engineering). First founder worked as a faculty member at a leading institute of technology and had 5-6 years of consulting experience in the area of networking. Second founder was running a successful family owned business related to manufacturing customer premise telecom equipment such as Modems. The third co-founder had about two years of experience related to software development with a major Indian company. Neither the first nor the second founder gave up his job to start the company; third founder was on a look out for a suitable job and decided to pursue entrepreneurship under the guidance of first founder (his advisor during post graduation).

The driver behind the business was that it was recognized that future networks would essentially be Internet Protocol (IP) based packet networks. Founders of company C3 were looking to develop a multi service interface that could use the existing infrastructure but provide the data, voice and video capabilities with minimum change in the equipment, minimum CapEx and highest quality of service. They decided to develop with Ethernet at the core of the technology as it was well understood and simple and cost effective to deploy. C3 was able to solicit investment from a US based VC with proven credentials in telecom related investment as well as SIDBI, an India based venture funding company. The company went forward with its plans of development and did achieve limited success in its development efforts and was able to successfully test its earlier version of product with one of the clients although it faced several problems in manufacturing high end hardware in India. But due to sudden changes in the business environment of its only prospective client coupled with rise of wireless broadband, it could not sustain in the market for long and was shut down in mid 2007. C3 also received a patent for its efforts related to development of an adaptation layer for communicating voice over Ethernet in 2005. 


\subsection{Company C4:}

C4 was founded in Bangalore in the year 2004. The two founding members were highly educated with post graduate degrees in management and graduation in technology (one with electronics engineering and other with computer science). Both founding members were first generation entrepreneurs without any prior start-up experience. The founders worked for well known software companies in their telecom software division and also worked for a telecom related start-up in various technical and managerial positions. They could sense a business opportunity for developing sub-components for speeding up product development in companies engaged in mobile applications and this led them to start their own company. One of the founders took on the role of CEO and other became the technical director.

They developed a several components for mobile application development and then in 2005-06 tried to move into m-commerce with a suite of products enabling m-ticketing, logistics etc. However, soon they realized the lack of volumes in m-commerce related business and moved to Bluetooth based products to reduce their dependence on the TSPs. C4 came up with innovative idea of transforming community centers into Bluetooth enabled zones for promotion and advertising over existing mobile handsets. C4 completed its development work by early 2007 and was able to bring its product into the market by converting a famous retail mall in Bangalore as the first Blue-Fi enabled mall in India. C4 subsequently acquired several new clients in the same space. By $2008 \mathrm{C} 4$ was among pioneers of Bluetooth based media companies in India. It not only sets up a Bluetooth network using its product but also maintains the network for their customers. C4 has about 30 employees and mostly sells through a revenue share model where in the retailers pay them a fixed fee for their product and the maintenance of the existing network. C4 received its first external funding to the tune of USD 250,000 from VC's in 2006 and has been looking to spread its Bluetooth zones across a 1000 centers in India.

\section{Identification of components of technological capability:}

As per our explanation in section 3.2 we begin our analysis process by listing all possible technological activities and identifying activities that could be classified as technological capabilities for further detailed analysis. An exhaustive list of technical activities conducted by the firms has been identified from case descriptions and they include the following activities, 
1) Architectural design

2) Prototype development

3) Testing

4) Product adaptation

5) Scale-up of production/development

Next we discuss above activities across firms by invoking instances and examples from our case studies to help us in our first level of analysis.

1) Architectural design:

a) All the firms that we studied began their development journey from design, although it was not a formalized process with extensive documentation like in established firms but was more like a shared vision among the founding team.

b) Design was guided by a low cost philosophy and included both hardware as well as software under its gambit. So design activity was spread over different levels of granularity.

c) All our firms also made appropriate choices regarding development environment and other software platforms which were important for overall product.

d) All the firms under study undertook several component level changes to offer the required benefits to their customers matching the available equipment or software in the market. They brought India centric changes to the product to serve their customers better.

The very fact that the firms wanted to offer cutting edge products in a domain which was dominated by multinationals necessitated specific changes in the product and these could only be incorporated at the architectural level. The basic requirement for the process was acquaintance with existing designs and its limitations as well. It was a critical activity and it was also realized that unless design was taken to certain level of excellence the product could not be realized. The process was iterative and finally it lead to overall designs that brought out product improvements in $\mathrm{C} 1$ and $\mathrm{C} 2$, whereas, it enabled a new paradigm of voice delivery in the case of $\mathrm{C} 3$ and a completely new application in the case of $\mathrm{C} 4$. So the very success of product functionality being achieved by telecom start-ups and the confidence of the entrepreneurs in delivering the intended functionalities can be considered as proxies of a well performed design activity. Based on the above description we can conclude that the architectural design skills of the start-ups are appropriate candidate to be considered as technological capability of the firms. 
2) Prototype development:

This included activities such as establishing the development environment including manufacturing (if required), entire algorithmic implementation or code writing exercise, and assembly of various subsystems to achieve the complete operational product.

a) $\mathrm{C} 1, \mathrm{C} 3$ and $\mathrm{C} 4$ outsourced most of their hardware related manufacturing but embedded components were developed in-house to ensure interaction between hardware and software.

b) All firms under study completely developed their own software related to specific algorithms, developed complete protocol suite and also graphic user interfaces (GUI).

c) Across the firms entrepreneurs have identified integrating the sub-components as critical for the product to function and it involved writing additional specific protocols.

All firms have acknowledged that they were comfortable with any software coding related activity of any scale but their understanding of hardware manufacturing was limited. So the activity related to hardware was more about choosing the right vendor to develop plastic circuit boards (PCB) and other components like amplifiers etc. Although the firms designed the entire hardware they did not possess the resources or experience to manufacture these in-house. This choice of vendors too was limited as only handful vendors could develop the high end components that were required by the firms. So the hardware vendor choice alone, although important cannot be a technological capability of the firm.

However, across the firms development and implementation of algorithms was consistently done well and this enabled the product to be realized. This was the actual development related activity and so was critical for the entire project to succeed. Based on the above description it can be concluded that, this skill of algorithmic implementation is the appropriate candidate for further exploration as a technological capability among the sample start-ups.

3) Testing:

a) Among all the firms initial focus was only on prototype development and not on testing.

b) Testing activities were started in response to customer requirements for robustness, and mostly included writing of a few test cases by the developers themselves. For instance in C2 first test cases were developed on the basis of benchmark specifications laid out by one of their large ISP client.

c) Across all our sample firms the most comprehensive testing was done by the clients when they installed the products in their own network or context. In case of $\mathrm{C} 4$ testing had to be done in a retail mall like environment. 
d) The usage of automated testing tools was non-existent given the prohibitive cost of such tools but automated testing is the norm in all the established companies as it enables a certain level of quality and also ensures consistency.

e) Although separate testing teams were created in C1 and C2 (in C2 the after sales support team also functioned as a makeshift testing team) but the general level of activity was not significant and was restricted to manual check list confirming functionality of various modules. C3 and C4 did not have a separate test team.

The state of testing has been well summed up by one of the senior employee involved in project management activities at $\mathrm{C} 1$,

"I would say that we are only $20 \%$ there still $80 \%$ i mprovement is needed, so testing is going on and test process is there but in my opinion it is very basic, primitive... But there is no precise definition of what is the input, what is the output, what are the different test conditions and mainly there is no automation of test cases which is important."

According to the CTO of $\mathrm{C} 2$,

"But still we do not say that we are a majorly proc ess driven or anything like that. But at least those things [testing] are there and I can say that testing does happen."

So based on the above description, we say that although basic testing did exist and was critical for the start-ups but extensive testing was not being done. The firms neither had the resources nor the training related to high end testing as is the norm in established firms in software or telecom sector. Testing activities were neither well performed nor process driven from the descriptions provided by the entrepreneurial teams. It is not an activity that can be classified as a candidate for technological capability.

4) Product adaptation:

a) All the case firms have identified product adaptation as an important activity to enable selling of the developed product.

b) C1 and C2 successfully incorporated the feedback from first customers about the product and have acknowledged the robustness that it brought to the product. C3, however, was bogged down by its other developmental commitments and could not attend to feedback as consistently and rapidly as the other firms. In C4 adaptation was based on their roadmap and performance criterion but not on feedback.

c) $\mathrm{C} 1$ as a part of adapting changed parts of code and improved exception handling for enabling continuous operation as required by client. $\mathrm{C} 2$ worked on a new billing module, brought in 
new way of handling codecs and finally re-wrote large parts of the application to improve the product. $\mathrm{C} 4$ made modifications to antennae design for outdoor setting as well as developed better handheld device identification method for their product.

Further evidence of adaptation as a critical activity can be had in the form of the following quotes from CTO of $\mathrm{C} 2$,

"That is when [on feedback] we did the prepaid bill ing and even now we have a very strong prepaid billing module, the way we had implemented it, the architecture of it is really good...That is when major improvements took place in the product, major stability was brought in, it was out of hot oven initially but it was completely perfected, it became that kind of product that you could sell it to anybody only because of company X".

Similarly, CEO of $\mathrm{C} 1$ too recognized the importance of adaptation as an activity,

"I would say that a start-up needs a guy with a vis ion and a guy who is looking at the market and making sure that we are making a product that is sellable and an engineering team that quickly adapts the particular realization into a product".

Even $\mathrm{C} 3$ realized and acknowledge the role of adaptation and they made changes like VDSL to ADSL port interface change on the requirement of a prospective customer but apart from this they were not proactive on this front. Overall it can be concluded that all our sample firms consider the activity as critical, all but $\mathrm{C} 3$ have performed the adaptation related activities well and $\mathrm{C} 2$ even tried to bring in some routinization in the form of collection and dispersal of data from clients to development team. It can be safely concluded that product adaptation is a candidate set for technological capability among the start-ups.

\section{5) Scaling-up of production/development:}

This activity was particularly relevant for hardware oriented firms. Only $\mathrm{C} 1$ showed an inclination towards scaling up of its production capacity. $\mathrm{C} 1$ made especial efforts towards establishing material flow of the process, decision making on rules for inventory handling, removing redundancies in the development in order to improve the output. However, the production manager at $\mathrm{C} 1$ pointed out that it was very difficult to make the people toe a fixed line and follow processes even after they were formalized to some extent. The team was used to work in an ad-hoc manner and was very slow to respond to process based work flow even when processes were simple and established after mutual consent. According to the production manager at $\mathrm{C} 1$,

"The real problem is that the team has been working in a start-up mode for say last 3-4 years and it is very difficult to get them to follow a project mind. That is our main difficulty". 
Firm C3 and C4 did have discussions among themselves regarding the scaling up but it was not followed up with any concrete action towards streamlining of production or development process. Only $\mathrm{C} 1$ made some effort towards establishing processes but given that the sales that the firm made were software based and not complete hardware the scaling up played no role in commercialization, though it may be expected to play an increasing role going ahead in the growth of $\mathrm{C} 1$. With no further evidence regarding scale-up we can not consider this activity as critical or well performed by the firms and as such it cannot be classified as candidate for further exploration as capability.

Our criteria of identification brings us to the following results,

Table-2: Identification of technological capabilities

\begin{tabular}{|l|l|l|l|l|}
\hline Activity & $\begin{array}{l}\text { Identified as } \\
\text { critical }\end{array}$ & $\begin{array}{l}\text { Performed } \\
\text { well }\end{array}$ & Routinized & $\begin{array}{l}\text { Identified as } \\
\text { capability }\end{array}$ \\
\hline Architectural design & Yes & Yes & No & Yes \\
\hline $\begin{array}{l}\text { Prototype development } \\
\text { (algorithmic implementation) }\end{array}$ & Yes & Yes & No & Yes \\
\hline Testing & No & No & No & No \\
\hline Product adaptation & Yes & C1, C2, C4 & $\begin{array}{l}\text { Limited to } \\
\text { C2 }\end{array}$ & Yes \\
\hline $\begin{array}{l}\text { Scale-up of } \\
\text { Production }\end{array}$ & No & No & $\begin{array}{l}\text { Limited to } \\
\text { C1 }\end{array}$ & No \\
\hline
\end{tabular}

\section{Detailed analysis:}

From our first stage analysis we identified that the start-ups performed three groups of activities particularly well and they are architectural design of their product, algorithmic implementation as a part of software development and product adaptation. The objective of detailed analysis is to bring together the different elements from all four case studies, delve deeper into each of the identified capabilities to identify their sub-components, develop dimensions to understand their characteristics and establish linkages between the capabilities.

\subsection{Architectural design capability:}

The first step in designing architecture for the product is setting a direction or a development philosophy that would guide the entire development process. Among our start-ups, low cost has been the guiding principle for development. All design decisions were impacted by this intent. Below we present three distinct design levels with the aid of instances from our case descriptions for understanding overall architectural design. The three design levels are the concept level, component 
level and interface level design. Concept level deals with idea and top level view of the product, component level and interface design look into further detailed aspects of components and their integration into a functioning product.

6.1.1 Concept level design: Concept level design represents the detailed top level idea of the product identified as opportunity by the entrepreneurs. In other words, it is the most basic and most feasible abstraction of the product design by the team. During concept level design, the design team identifies the roles of major components (both hardware and software) that need to be brought together to achieve desired end functionality or final output. For a concept level design change, the product should either be completely new to world, a new scientific development altogether (the fundamental principle behind the product should change, a new functionality) or the operating paradigm needs to change (same functionality as before but with a new technology) such that it was never conceived in the product family previously. Change in configuration, by affecting existing modularity of the product or drastic scalability changes for specific contexts are also considered a part of concept level design.

All our start-ups were engaged in developing products wherein the basic functionality had been in existence since almost a decade in some form or the other. For example, the basic principles behind the development of a base station (C1), VoIP software infrastructure (C2), first mile multi-port access (C3) and Bluetooth based access (C4) have been well understood for the past several years. However, the uniqueness of the start-ups emanated from either adapting the underlying technology to a suitable scale or adopting a new operating paradigm for creating low cost India centric products. For example, C1 developed a lower capacity, compact WiMax BS with an integrated network management system for local/individual usage at a time when base stations were perceived as only mass scale, expensive equipment in India. C2 was engaged in developing low cost, ready to use VoIP software infrastructure for service providers in India. In terms of change in operating paradigm, C3 was working towards circuit emulation over Ethernet when no similar product was in existence and it represented complete change from VoIP which was based on Internet protocol. C4 developed the idea of Blue-Fi zone over an entire community space such as a retail mall when no similar application of Bluetooth technology was being used.

Although none of the product concept was a breakthrough in the scientific sense, it did represent a change in the way functions of individual parts were perceived from those in the existing designs in the market. In other words the firms were engaged either in bringing a change in operating paradigm or in re-configuration within specific constraints to achieve the requisite functionality. (Existing design stands for those designs which were being used in family of products that were similar to the ones being conceived by the start-ups under study in terms of functionality). 
For concept level design, understanding of the telecom domain plays a major role and requires complete familiarization with existing designs as well as their constraints in terms of limitations and existing problems. The concept level design for a completely new to the world product is a visionary activity but concept level design for an existing product is perceptibly less complex and low in risk but highly creative process. The designer could bring in aspects of different level of modularity or integrability between the components, visualize different configurations suited to varying objectives such as high performance, low cost etc. by the virtue of design.

The design changes incorporated by the start-up firms enabled them to achieve specific benefits, it resulted in better service provisioning for $\mathrm{C} 1$, higher flexibility due to modularization for $\mathrm{C} 2$, better utilization of data ports due to aggregation at two levels for the clients of C3 and resulted in elimination of service provider intervention with file exchange at no cost to client for $\mathrm{C} 4$. These design changes were associated with the entrepreneurial team's skill at visualizing alternate configuration and then evaluating and deciding on a feasible configuration guided by the contextual requirement such as similar functionality as the existing design but lower cost. Based on the above discussion we propose that,

Proposition 1: Telecom start-ups develop new operating paradigms in existing products or engage in re-configuration of existing products to meet specific objectives leading to the evolution of new designs and thereby contributing positively to the architectural design capability.

6.1.2 Component level design: This occurs at a more granular level wherein each major part identified in the concept level design is taken up for detailed design. It could be an incremental improvement in existing component or a component which has not being used for the specific purpose could be adapted for use in the upcoming product leading to cascading changes elsewhere. Important aspects of component level design are segregation of strategic and non strategic components, knowledge regarding functions of individual components and their interactions and familiarity with various off the shelf components available in the market such as the product portfolio of chipset manufacturing companies and even available software components. The segregation into strategic and non-strategic components enables the start-up to focus its energies towards identified strategic components to bring about any improvement/modification within the components. The evaluation of different components available in the market with respect to performance, price, availability in the future as well as the stature and financial position of the company needs to be carried out. 
In case of hardware dominated products, the choice of chipset determines the further design of hardware circuit and other functional components. For example, the small WiMax base station being developed by $\mathrm{C} 1$ was to be used for a smaller subscriber base within a limited distance, so utilizing a conventional chipset was not appropriate as it would have led to escalation in cost and non usage of additional features in the chipset. $\mathrm{C} 1$ chose a chipset that was until then used only in the customer premise equipment (CPE). By doing so, $\mathrm{C} 1$ wanted to exploit the economies of scale, that are inherently more pronounced on the CPE side as compared to the base station side thereby developing an India centric low cost base station. With the change in chipset, corresponding software such as dynamic hopping algorithms to minimize interference, jitter control algorithms etc. needed to be developed to enable the chipset function like a base station. In the case of $\mathrm{C} 3$, completely new chipsets were identified for data and voice applications, work was carried out for design of software for jitter and buffer control and a network management system for controlling two levels of aggregation was designed achieve the requisite functionality. Although $\mathrm{C} 4$ did not go in for a new chipset for their hardware design but they had to work on the radio frequency equipment and associated circuitry. Additionally, design for embedded applications too was worked upon by C1, C3 and $\mathrm{C} 4$.

The choice of software platforms to be used in the development is also made during component level design. As a follow up for the low cost strategy followed by the start-ups, all the firms adopted open source platforms as well as off the shelf components right from the beginning. This was justified on the basis that open source platforms helped in reducing the cost of development and help in speeding up the development activity.

Design of specific algorithms for improving the performance of telecom related products such as jitter control, buffer control etc is accomplished as a part of software component design. As an example in the case of $\mathrm{C} 2$, component level changes were made for the storage of audio codecs instead of real time conversion as was common to most existing designs in the interactive voice response (IVR) module. Understanding of these complex algorithms involves going through journals or other technical documents and thus involves abstraction on the part of the designer. Additionally software design related to graphic user interface as well as the network management systems is also decided during the component level design. Apart from software and hardware individually, design has to be worked out for the development of embedded software which enables interaction between the components and this is a very complex activity. An underlying aspect of all the above design related work is adhering to interface related constraints as any component design can be meaningful only if it supports the existing interface. Based on above discussion we propose that,

Proposition 2a: Ability to identify specific components to modify/re-configure, make appropriate 
hardware component choice and software platform choice within pre-specified standard interface constraints contributes positively to the architectural design capability of start-up.

Proposition 2b: Ability to conceptualize and specify embedded components, performance enhancing telecom specific algorithms and hardware circuits in-house within pre-specified standard interface constraints contributes positively to the architectural design capability of the start-up.

6.1.3 Interface design: The third component of architectural design is the way interfaces between various components of the product is conceptualized. The product by virtue of its interface design may be strongly coupled or loosely coupled. In the telecom space the external interfaces are well defined in the form of standards but their individual interpretation may vary from one company to another. Interpreting standards is a critical activity as most external interfaces have to be standardized to enable interconnection with a plethora of third party equipment. Internal interfaces between components are also based on various protocols which on improper interpretation may impact the overall performance of the product. The main activity that needs to be accomplished is the choice of appropriate protocols for the interfacing with other components or products. Although, knowledge related to protocols is not readily accessible and is mostly acquired on the job in specific organizations, both external and internal interface design was carried out in-house among all the startups. For example, $\mathrm{C} 1$ designed its versions of protocols between the base station and the network management system, C2 worked on H.323 and SIP, C3 had to design its own version of SNMP agent and $\mathrm{C} 4$ had to work on object exchange protocols (OBEX) in order to make the product work. Also each of the firms designed their own complete protocol suites for the products. The telecom start-ups were able to successfully choose and design various standards and protocols for their products.

In certain situations the existing protocols or standards may not be best suited or might be proprietary. In such cases either a protocol may need to be re-conceptualized from scratch guided by the existing protocols or the existing protocol may need to be enhanced or modified to serve the purpose like $\mathrm{C} 2$ had to design its proprietary NAT traversal method. Both the above activities are technologically difficult and complex. Since large part of the definition of these protocols has a tacit component to it, even well written journal papers or other standard documents available on these protocols are not sufficient for thorough understanding of these protocols. This has been put very effectively by a senior developer at $\mathrm{C} 1$,

"Reading the standard was helpful in a way to under stand how the protocol works and how the things should be done but finally you need to apply your experience in those things [design]".

Based on above, we propose,

Proposition 3a: Ability to conceptualize the logical design of complete protocol suite as well as 
enhancement or modification of existing protocol design for the product contributes positively to the architectural design capability of the start-up.

Proposition 3b: Ability to conceptualize external interface standards (to enable compatibility with third party equipment) and internal interface standards (to enable functional integration) contributes positively to the architectural design capability of the telecom start-ups.

All the discussion has been summarized in table- 3 along with performance summary of our case firms.

Table 3: Components of architectural design of the product

\begin{tabular}{|c|c|c|c|c|}
\hline Architectural design & $\mathrm{C1}$ & $\mathrm{C2}$ & $\mathrm{C3}$ & $\mathrm{C4}$ \\
\hline a) Design philosophy & $\operatorname{cost}$ & ow cost & ow cost & ow cost \\
\hline $\begin{array}{l}\text { b) Concept level design } \\
\text { - Change in functionality with respect to } \\
\text { (w.r.t.) existing products } \\
\text { - Change in operating paradigm } \\
\text { w.r.t. existing design } \\
\text { - Change in configuration } \\
\text { from existing design } \\
\end{array}$ & $\begin{array}{l}\text { No } \\
\text { No } \\
\text { Yes }\end{array}$ & $\begin{array}{l}\text { No } \\
\text { No } \\
\text { Yes }\end{array}$ & $\begin{array}{l}\text { No } \\
\text { Yes } \\
\text { New design }\end{array}$ & $\begin{array}{l}\text { No } \\
\text { Yes } \\
\text { New design }\end{array}$ \\
\hline $\begin{array}{ll}\text { c) Component level design } \\
\text { - } & \text { No. of component level changes } \\
\text { - } & \text { Extent of change from dominant } \\
\text { design in market (due to chipset) } \\
\text { - Appropriate choice of hardware and } \\
\text { - software platforms } \\
\text { - Self design of hardware circuits } \\
\text { - Self (logical) design of embedded } \\
\text { - } \text { Semponents } \\
\text { - } \text { specific algorithms } \\
\text { Self design of GUI and } \\
\text { network management system } \\
\end{array}$ & $\begin{array}{l}\text { High } \\
\text { High } \\
\text { Yes } \\
\text { Yes } \\
\text { Yes } \\
\text { Yes } \\
\text { Yes }\end{array}$ & $\begin{array}{l}\text { Low } \\
\text { Low } \\
\text { Yes } \\
\text { No } \\
\text { No } \\
\text { Yes } \\
\text { Yes }\end{array}$ & $\begin{array}{l}\text { High } \\
\text { High } \\
\text { Yes } \\
\text { Yes } \\
\text { Yes } \\
\text { Yes } \\
\text { Yes }\end{array}$ & $\begin{array}{l}\text { High } \\
\text { Low } \\
\text { Yes } \\
\text { Yes (partial) } \\
\text { Yes } \\
\text { Yes } \\
\text { Yes }\end{array}$ \\
\hline $\begin{array}{l}\text { d) Interface design } \\
\text { - Interface standardization } \\
\text { - } \quad \text { (external and internal) } \\
\text { - Self (logical) design of protocol suite } \\
\text { - } \quad \text { Protocol enhancement } \\
\end{array}$ & $\begin{array}{l}\text { High } \\
\text { Low } \\
\text { Yes } \\
\text { No } \\
\end{array}$ & $\begin{array}{l}\text { High } \\
\text { High } \\
\text { Yes } \\
\text { Yes } \\
\end{array}$ & $\begin{array}{l}\text { High } \\
\text { Low } \\
\text { Yes } \\
\text { No } \\
\end{array}$ & $\begin{array}{l}\text { High } \\
\text { High } \\
\text { Yes } \\
\text { No } \\
\end{array}$ \\
\hline
\end{tabular}

On comparing our conceptualization of product architecture with existing literature, we see that although it is similar to Ulrich (1995) scheme but it is extendable to any level of granularity to identify a technological change as well as it is independent of final product being software or hardware. Our conceptualization overcomes Ulrich's functionality dependence (Ulrich, 1995; Fixson and Park, 2008) as in the telecom domain the functionality could still be the same with a change in the underlying concept e.g. is the change in way data is sent over the radio waves in GSM and CDMA. Our conceptualization also incorporates Henderson and Clark's (1990) framework of architecture as 
components and interfaces and further enhances it by capturing business logic of the product as important dimension in determining product architecture design.

\subsection{Algorithmic implementation capability:}

Software development forms an important activity for all the firms of our sample irrespective of the fact that they may be completely software based or have products with both hardware and software components. However software development is a broad term comprising end to end developmental effort from requirement gathering to specification development, actual algorithm implementation, testing, validation and verification etc. Our sample of start-ups has been consistently successful at implementing complex algorithms (code writing specifically) from scratch. According to the CEO of $\mathrm{C} 1$,

"We developed the complete protocol stack and the necessary drivers...we have developed efficient software algorithms which allow us to program a low end microprocessor".

Similarly according to CTO of $\mathrm{C} 2$,

"We were in the process of building the stack right from the scratch till the complete product we have built on our own, that is why the complete IP of this lies with us, we have no actually borrowed anything from anywhere but written it ourselves".

Implementation of embedded codes, protocol stacks and an element management system or a network management system across all firms, buffer control algorithms in company $\mathrm{C} 1$, jitter control and latency control algorithms in both $\mathrm{C} 1$ and $\mathrm{C} 3$ as well as providing appropriate graphic user interface (GUI) for the users in $\mathrm{C} 1, \mathrm{C} 2$ and $\mathrm{C} 3$ are all examples of success at code writing. This required software development team to understand the design requirements and then convert these shared mental models into working realizations. Exploiting the algorithm development ability enabled the start-ups to overcome several hardware related problems which could be handled better by software written for the specific purpose. For instance, the up-gradation in the product by $\mathrm{C} 1$ was no longer hardware based even when it was scaled up. It needed only a soft upgrade, thus, saving cost and reducing the operating expenses for the customer. Implementing protocol stacks, embedded components and other standards also involved bringing about integration among the disparate subsystems to make the product fully operational. Based on above discussion we say that,

Proposition 4a: Ability to articulate and transform self designed embedded components, specific network related performance enhancing algorithms and own protocol stacks into workable codes for 
the product contributes positively towards the algorithmic implementation capability of the telecom startup.

Existing literature in management is scant on the aspect of recognizing the capability related to conversion of cognitive mental framework or algorithm into a software code. However, scholars like Ethiraj et al., (2005); Humphrey, (1989) and Jalote, (1997) have made a mention of code writing skills within project management capabilities of the IT companies. Ethiraj et al., (2005) have also emphasized on the importance of building codes in accordance with design effectively and efficiently for large firms with distributed teams. This transformation of abstract design into an explicit workable code using tacit coding skills is a central part of this capability among the start-ups.

However, our sample start-ups were weak on the process side given their resource constrained nature. Extensive process focus (especially best practices) sets the established companies apart from the startups. With several employees having prior experience of working with large software companies or MNC's known for following strict processes (such as the CMMI) the start-ups were well versed with the best practices of the software industry (Ethiraj et al., 2005). But the start-ups adopted only those practices that were felt relevant by the employees in terms of contributing to quality and consistency in their work. Examples of such adoption was version control adopted by company $\mathrm{C} 1$, extensive error reporting adopted by company $\mathrm{C} 2$ and high level of development related documentation efforts in $\mathrm{C} 3$ and $\mathrm{C} 4$. But these were mostly isolated activities done selectively rather than being a part of institutionalized process framework. Although following processes is costly, following of appropriate processes brings in better quality of products as was evident by the respective activities in each of the cases. In $\mathrm{C} 1$, adoption of version control enabled the company to offer the best suited versions to their customers with optimum features. In C3 and C4, extensive documentation enabled the firm to quickly train the new employees and also enabled better interaction among design team. Based on above discussion we postulate, 
Proposition 4b: Ability to pick and choose appropriate best practices (such as version control, detailed documentation etc.) among the start-ups in order to improve the quality of product without corresponding escalation in cost contributes positively to the algorithmic implementation capability of the firm.

Above discussion along with performance of case firms has been summarized in table- 4

Table 4: Algorithmic implementation components

\begin{tabular}{|l|l|l|l|l|}
\hline Algorithmic Implementation & C1 & C2 & C3 & C4 \\
\hline $\begin{array}{l}\text { a) In-house successful implementation of } \\
\text { - Network related algorithms }\end{array}$ & Yes & Yes & Yes & No \\
- Protocol stacks & Yes & Yes & Yes \\
Yes & Yes \\
- EUI and NMS & Yes & No & Yes \\
Yes
\end{tabular}

\subsection{Product adaptation capability:}

Start-ups need to consistently adapt their products to enter the market in the first place and then to remain competitive. Here we look at product adaptation as a group of all those activities that enable a start-up to modify/rectify/improve/customize its product so that it can be brought to the market but that do not change the concept level design. Based on our interaction with entrepreneurs and data analysis it emerges that adaptation is critical for start-ups in telecom domain because;

a) Lack of sufficient data on market behaviour and lack of resources among the start-ups to conduct market research

b) Lack of appropriate testing facilities due to resource crunch

As a result either the earliest versions of the product are incomplete in terms of benefits that they provide or are not up to the mark in terms of quality. In our sample firms' context if the product had to go into an active and densely loaded network, its improper functioning could bring down the entire network of the service providers. This has implications for the service providers who are engaged in cut throat competition amongst each other and any such downtime can lead to customer churn. Intuitively it can be argued that product adaptation will be more pronounced if the developed product is far apart from the actual requirements of the customers. 
The adaptation may be either voluntary wherein the development team realizes certain shortcomings in the product and resorts to change of course that is required or it may be customer driven as a result of early customer feedback. All the start-ups in our sample with the exception of $\mathrm{C} 4$ were more active in adaptation on customer requests during the initial days. For example, in the case of $\mathrm{C} 1$ the customer requirement was that the product needs to function in the network with no down time for 15 consecutive days, but this could not be tested till product was installed in a real life network. The $\mathrm{C} 1$ development team then brainstormed among themselves and realized that they needed to rewrite certain parts of the code and improve exception handling. Similarly, C2 after installation in customer's network realized that it needed to create a billing module and integrate it with the existing billing system of customer to make the product useful and this involved learning and implementing an entirely new protocol called radius. C3 was required to add VDSL based ports to its product by the prospective customer. All the modifications were important for improving the product and enable its sales. However, as the start-ups evolved they started having their own releases at definite intervals with a pre-decided focus on certain improvement. For example, $\mathrm{C} 2$ re-wrote a large part of their code to improve the performance of the product voluntarily.

The difference observed in adaptation by $\mathrm{C} 4$ can be accounted for by analyzing the nature of its product. Unlike the other firms $\mathrm{C} 4$ did not have network operators as its clients who could give feedbacks to them. In fact no one was in a position to give them any feedback and they had to seek out the problems and work on modification of the product all by themselves. They successfully enhanced the stacks on a regular basis, developed advanced handheld instrument identification device which was critical for performance improvement and even modified design for antennae depending upon the external environment e.g. inside a mall or an open stadium.

All our sample firms have reported that lack of resources forced the same team to function both as development team and after sales support team tending to customer requests for modifications in the product. According to the $\mathrm{CTO}$ of $\mathrm{C} 1$,

"All give you problems saying that this is not work ing, that is not working and you need to solve those problems no matter what. So all my development works stop, see this is one hurdle as my team is limited and the same team has to look into the problems as well as further development... The requirements are prioritized and most of the times their problems are genuine and also being a company like we are we cant say we have prioritized and wait for some more days. If we can discuss and say that it not a priority immediately for us or the customers then we can wait but otherwise we have to do it on priority. More than development time is spend on the enhancements that the customer asks for"

The benefit was that the team could quickly solve the customer complaints due to their inherent understanding about the product but the flip side was that it hampered the over all development plan 
for the upcoming releases of the product. So a trade-off has to be made in following the roadmap for development envisaged voluntarily and customer requirements and this affects the direction of technological evolution of the firm. Based on above discussion we can say that,

Proposition 5a: Ability to manage trade-off between self driven adaptation and customer driven adaptation in product based telecom start-ups impacts the development of overall product adaptation capability of the firm.

The process of product adaptation among firms include the following steps, obtaining the relevant information about the product from the market, articulating the need for change, identifying the changes that need to be made at various levels in the product and finally implementing those changes and testing the modified product. However, only two of the start-ups in the study C2 and C4 had a separate customer service team which could contact the development team about the issues at hand. The marketing team played an important role in getting the appropriate feedback to the development team. Hereafter once the development team is apprised of the problems in the product the technological articulation of the modification required takes place and is implemented by employing the architectural design and algorithmic implementation capabilities of the firm. It can be argued that product adaptation is a skill formed by the integration of marketing capability and technological capability as the modification or enhancement of the product requires appropriate inputs from the market. Based on the above discussion we propose that,

Proposition 5b: Stronger market information acquisition, architectural design and algorithmic implementation capability contributes positively towards product adaptation capability of the startups.

\subsection{Summarizing:}

We summarize our finding from analysis that we conducted in the table-5. We also highlight differences between start-ups and established firms in the context of identified capabilities. The differences between start-ups and established firms in terms of individual constituents of capability, we see the existence of two dimensions. First is with respect to ability to visualize alternate configurations and choice of appropriate hardware and software platforms, which is of extreme importance to start-ups as they can not choose best possible components due to resource constraints do not apply to the established firms. Similarly, problem of managing trade-offs between technical trajectory for a product and customer forced modifications has not been recorded for established firms in literature. These are what can be labeled as the "basic differences" between constituents of technological capability among the start-ups and established firms. Second dimension is with respect to difference in the level of excellence and maturity in the execution of specific constituents of 
technological capabilities. As is expected it is this maturity and excellence achieved over the years that is responsible for high quality among the products of the established firms and high process focus brings in consistency in technological development. These differences could be labeled as "scalar differences" between the established and start-up firms.

Table 5: Summary of findings related to technological capability

\begin{tabular}{|c|c|c|c|}
\hline Capability & $\begin{array}{l}\text { Source/ } \\
\text { Driven by }\end{array}$ & Constituents & Peculiarities \\
\hline $\begin{array}{l}\text { Architectural } \\
\text { Design }\end{array}$ & $\begin{array}{l}\text { Technological } \\
\text { knowledge }\end{array}$ & $\begin{array}{l}\text { - Ability to visualize } \\
\text { alternate configurations } \\
\text { - Ability to identify } \\
\text { strategic components to } \\
\text { modify, make } \\
\text { appropriate hardware and } \\
\text { software platform } \\
\text { choices } \\
\text { - Ability to conceptualize } \\
\text { embedded components, } \\
\text { hardware circuits and } \\
\text { telecom specific } \\
\text { algorithms } \\
\text { - Ability to incorporate } \\
\text { high external interfacial } \\
\text { standardization } \\
\text { - Ability to enhance } \\
\text { protocols and design } \\
\text { complete protocol suite }\end{array}$ & $\begin{array}{l}\text { Small, multi } \\
\text { disciplinary } \\
\text { team, } \\
\text { not process } \\
\text { driven, based } \\
\text { more on a shared } \\
\text { vision for future, } \\
\text { do not own prior } \\
\text { patents and } \\
\text { design process } \\
\text { draws heavily } \\
\text { from existing } \\
\text { components and } \\
\text { is not done from } \\
\text { scratch }\end{array}$ \\
\hline $\begin{array}{l}\text { Algorithmic } \\
\text { Implementation }\end{array}$ & $\begin{array}{l}\text { Technological } \\
\text { knowledge }\end{array}$ & $\begin{array}{l}\text { Ability to articulate } \\
\text { design requirements into } \\
\text { workable codes such as } \\
\text { implementing entire } \\
\text { protocol suite } \\
\text { - Ability to choose } \\
\text { appropriate best practices }\end{array}$ & $\begin{array}{l}\text { Use of standard } \\
\text { practices not } \\
\text { wide spread, } \\
\text { issues of quality, } \\
\text { consistency }\end{array}$ \\
\hline $\begin{array}{l}\text { Product } \\
\text { Adaptation }\end{array}$ & $\begin{array}{l}\text { Market } \\
\text { orientation, } \\
\text { architectural } \\
\text { design, \& } \\
\text { algorithmic } \\
\text { implementation }\end{array}$ & $\begin{array}{l}\text { - Ability to formulate } \\
\text { customer/ product issues } \\
\text { into technological } \\
\text { problems and their } \\
\text { solutions } \\
\text { - Ability to manage trade } \\
\text { off between roadmap and } \\
\text { customer focused } \\
\text { modifications }\end{array}$ & $\begin{array}{l}\text { Small team and } \\
\text { minimum } \\
\text { process focus }\end{array}$ \\
\hline
\end{tabular}




\subsection{Complementarity with existing literature:}

We have identified the technological capability among the telecom start-ups as their architectural design skills, their algorithmic implementation skills and product adaptation skills. On comparison of our findings with the 3 P (Product, Process, Practice) framework (Basant and Chandra, 2002) we observe that each of the above mentioned capabilities comprises product related activities, process related activities and specific practices being followed by the firm. Most activities are product related since our context is start-ups and the activities are not heavy on the process side as the processes are yet to evolve to a maturity like in an established firm. Therefore application of above framework in a start-up without adaptation is not advisable and could as well borrow from our insights regarding telecom start-ups.

Moreover, existing literature (Barney, 1991; Grant, 1996; Teece et al., 1997; Eisenhardt and Martin, 2000) has been consistent in bringing forth the role of tacit knowledge and causal ambiguity or idiosyncraticity (Lippman and Rumelt, 1982; Dierickx and Cool, 1989; Reed and DeFillippi, 1990) in the capabilities of the firms. In each of the three capabilities we see an existence of significant tacit knowledge dimension. This corroborates that our results are in agreement with the existing paradigms of capability framework.

From the product life cycle perspective (Kim, 1997), all the firms that we studied were involved in development of products which were in their early phase across the world. As suggested by extant literature (Yli-Renko et al., 2001; Ethiraj et al., 2005), firms needed to assimilate and integrate their existing technological knowledge with knowledge acquired from external sources and make requisite improvements/adaptation (Kiel, 2004) to the acquired knowledge for taking the products to the market. All our start-ups tried to incorporate India centric benefits like low cost and appropriate scale to suit the clients, e.g. C2 needed higher traffic handling, C4 looking to convert community space to Blue-Fi zone (instead of kiosks) whereas $\mathrm{C} 1$ was looking at scaled down base station with no more than 10-15 subscribers for the single base station.

\section{Conclusion:}

Our work contributes to both theory and practice in many ways. From a theoretical standpoint our work is among the early work trying to bring together entrepreneurship and RBV literature to answer questions related to commercialization among start-ups thereby informing both the threads of literature in the process. Our approach has promising implications for future work focusing on understanding evolution of capabilities as well as studying strategic innovations among the firms as interaction between various capabilities of the firm (technological and marketing etc.) may form the 
basis of innovative behaviour among the firms. From technology management perspective insights from product development among start-ups might aid similar activities across established firms, enabling them in adopting lean and more cost effective techniques.

In the present work we establish a framework and utilize our framework comprising three pronged criteria, criticality, consistence \& excellence and routinization for identifying the technological capabilities. As our evidence points out routinization is not such a strong criterion for identification among the start-ups due to their early stage and even after commercialization routines are in a state of flux. We identify architectural design, algorithmic implementation and product adaptation as the components of technological capability among the telecom start-ups. We further dwell in depth to study each of these components to identify their sub-components. The successful implementation of telecom protocols and standards among the start-ups has been identified as critical for commercialization. We also contribute by proposing a scheme to classify product architecture irrespective of product being software or hardware. Evidence was presented for integration between marketing capability namely market information acquisition as a strong determinant in the development of product adaptation capability. We also point out that key difference in the technological capabilities between start-ups and established firms lie in level of excellence and maturation of a specific skill and high level of routinization. Clearly our work complements all the existing work on established firms in the context of technology capability literature ${ }^{3}$.

On the flip side we present evidence for lack of testing infrastructure among telecom start-ups as well as problems related to hardware manufacturing. These present a case for policy level intervention from government. For example R\&D organizations under government control could assist in testing and certifying the products of start-ups. On the hardware front urgent intervention seems the need of the hour. Existing incentives have not worked in developing a high end hardware manufacturing ecosystem. Possibly inviting investment through MNCs may help in plugging gaps in this area.

Through this work we have presented a snapshot of product based telecom start-ups and their issues in India but it can be speculated that on investigation in similar settings across other developing counties similar issues may emerge. Also we would like to mention that although our context was telecom but our approach can be extended to other high-tech start-ups in bio-tech or pharma sector which exist in regulatory environment in order to understand and identify their technological capabilities. However, propositions developed by us are a first step and they need to be validated statistically for greater generalizability. This would require development of instruments for measuring technological capabilities and insights from our study could go a long way in assisting future research in this area.

\footnotetext{
3 Authors would like to thank one of the reviewers for pointing this out.
} 
Another interesting area of future research could be interaction of different organizational capabilities and their impact on one another as well as on the firm performance. On a more broad level work on technology entrepreneurship in India is still in infancy and we hope our work motivates more work in this area.

\section{Acknowledgements:}

Authors would like to acknowledge the useful feedbacks from Prof. Rakesh Basant, Indian Institute of Management, Ahmedabad, and two anonymous reviewers for their comments.

\section{References:}

Afuah, A., 2002. Mapping technological capabilities into product markets and competitive advantage: The case of cholesterol drugs. Strategic Management Journal, 23 (2), pp 171-179.

Amit, R., Schoemaker, P. J. H., 1993. Strategic assets and organizational rent. Strategic Management Journal, 14(1), pp 33-46.

Basant, R., Chandra, P., 2002. Building technological capabilities in a liberalizing developing economy: Firm strategies and public policy. Economics of Innovation and New Technology, Taylor and Francis Journals, vol. 11(6), pp 1-23.

Bell, M., Pavitt, K., 1993. Technological accumulation and industrial growth: Contrasts between developed and developing countries. Industrial and Corporate Change, 2, pp 157-210.

Brixy, U., Kohaut, S., 1999. Employment growth determinants in new firms in eastern Germany. Small Business Economics, 13, pp 155-170.

Dierickx, I., Cool, K., 1989. Asset stock accumulation and sustainability of competitive advantage. Management Science, 35, pp 1504-1511.

Deeds, D.L., DeCarolis, D., Coombs, J., Dynamic capabilities and new product development in high technology ventures: An empirical analysis if new biotechnology firms. Journal of Business Venturing, 15, pp 211-229.

Dosi, G., Teece, D., 1993. Competencies and the boundaries of the firm. Center for Research in Management, CCC Working Paper No. 93-11, University of California at Berkeley.

Dutta, S., Narasimhan, O., Rajiv, S., 2005. Conceptualizing and measuring capabilities: methodology and empirical application, Strategic Management Journal, 26, pp 277-285.

Eisenhardt, K. M., 1989. Building theories from case study research. Academy of Management Review, 14(4), pp 532-550.

Eisenhardt, K. M., Martin, J. A., 2000. Dynamic capabilities: what are they? Strategic Management Journal, 21(10-11), pp 1105-1121.

Eisenhardt, K.M., Graebner, M.E., 2007. Theory building from cases: Opportunities and challenges. Academy of Management Journal, 50(1), pp 25-32. 
Figueiredo, P.N., 2002. Does technological learning pay off? Inter-firm differences in technological capability-accumulation paths and operational performance improvement. Research Policy, 31(1), pp 73-94.

Fixson, S.K., Park, J., 2008. The power of integrality: Linkages between product architecture, innovation, and industry structure. Research Policy, 37 (8), pp 1296-1316.

Grant, R. M., 1996. Prospering in dynamically-competitive environments: Organizational capability as knowledge integration. Organizational Science, 7 (July-August), pp 375- 87.

Helfat, C.E., 2000. The evolution of capabilities. Strategic Management Journal (Special Issue) 21 (10-11), pp 955-959.

Helfat, C.E., Peteraf, M.A., 2003. The dynamic resource-based view: Capability lifecycles. Strategic Management Journal, 24(10), pp 997-1010.

Helfat, C., Finkelstein, S., Mitchell, W., Peteraf, M.A., Singh, H., Teece, D.J., Winter, S.G., 2007. Dynamic capabilities: Understanding strategic change in organizations. Blackwell: Oxford, U.K.

Henderson, R., Clark, K., 1990. Architectural Innovation: The reconfiguration of existing product technologies and the failure of established firms. Administrative Science Quarterly, 35, pp 9-31.

Henderson, R., Cockburn, I., 1994. Measuring competence? Exploring firm effects in pharmaceutical research. Strategic Management Journal, 15, winter, pp 63-84.

Kim, L., 1999. Building technological capability for industrialization: Analytical frameworks and Korea's experience. Industrial and Corporate Change, 8 (1), pp 111-136.

Lee, C., Lee, K., Pennings, J.M., 2001. Internal capabilities, external networks, and performance: A study on technology-based ventures. Strategic Management Journal, 22 (6), pp 615-640.

March, J. G., 1991. Exploration and exploitation in organizational learning. Organization Science, 2, pp. 71-87.

Miles, M. B., Huberman, A. M., 1994. Qualitative data analysis: An expanded sourcebook, $2^{\text {nd }}$ edition. Thousand Oaks, CA: Sage.

Montealegre, R. (2002). A process model of capability development: Lessons from the electronic commerce strategy at Bolsa de Valores de Guayaquil. Organization Science, 13(5), 514-531.

Nelson, R.R., Winter, S.G., 1982. An evolutionary theory of economic change. Cambridge, MA: Belknap Press of Harvard University Press.

Nonaka, I., 1994. A dynamic theory of organizational knowledge creation. Organization Science, 5(1), pp 14-37.

Pan, S.L., Pan, G., Hsieh, M.H., 2006. A dual-level analysis of capability development process: A case study of TT\&T. Journal of the American Society for Information Science and Technology, 57, pp1814-1829.

Patel, P., Pavitt, K., 1997. The technological competencies of world's largest firms: Complex and path dependent, but not much variety. Research Policy, 26(2), pp141-156. 
Peteraf, M. A., 1993. The cornerstones of competitive advantage: A resource-based view. Strategic Management Journal, 14(3), pp 179-191.

Pettigrew, A.M., 1988. Longitudinal field research on change: Theory and practice. Organization Science, 1 (3), Special Issue: Longitudinal Field Research Methods for Studying Processes of Organizational Change, pp. 297-292.

Prencipe, A., 2000. Breadth and depth of technological capabilities in CoPS: the case of the aircraft engine control system. Research Policy, 29 (7-8), pp 895-911.

Schumpeter, J. A., 1934. The theory of economic development. Cambridge, MA: Harvard University Press.

Schumpeter, J.A., 1942. Capitalism, socialism and democracy. New York: Harper and Row.

Teece, D.J., Pisano, G., Shuen, A., 1997. Dynamic capabilities and strategic management. Strategic Management Journal, 18(7), pp 509-533.

Tether, B. S., Massini, S., 1998. Employment creation in small technological and design innovators in the U.K. during the 1980's. Small Business Economics, 11, pp 353-370.

Tsai, K., 2004, The impact of technological capabilities on firm performance in Taiwan's electronic industry. Journal of High Technology Management Research, 15, pp 183-195.

Ulrich, K.T., 1995. The role of product architecture in the manufacturing firm. Research Policy, 24, pp. 419-444.

Upadhyayula, R., Basant, R., Chandra, P., 2006. Building technological capabilities through strategic development of industrial clusters. Doctoral Thesis, Indian Institute of Management, Ahmedabad, India.

Wernerfelt, B., 1984. A resource-based view of the firm. Strategic Management Journal, 5(2), pp 171180.

Wagner, J., 1994. The post-entry performance of new small firms in German manufacturing industries. Journal of Industrial Economics, 42(2), pp 141-154.

Yeoh, P., Roth, K., 1999. An empirical analysis of sustained advantage in the US pharmaceutical industry: Impact of firm resources and capabilities. Strategic Management Journal, 20, pp 637-653.

Yin, R.K., 1994. Case study research: Design and methods (Vol. 5), Sage Publications. 